\title{
LBM-MRT simulation of vertical flow of a non-Newtonian fluid in a channel provided with obstacles
}

\author{
Mohammed Amokrane Belaidi ${ }^{1}$, Lyes Nasseri ${ }^{1^{*}}$, Rachid Nebbali ${ }^{1}$, Nabil Himrane $^{2}$, and Djamel Eddine \\ Ameziani ${ }^{1}$ \\ ${ }^{1}$ LTPMP Laboratory. Faculty of Mechanical and Proceeding Engineering, University of Sciences and Technology Houari \\ Boumediene, Algiers, Algeria; \\ ${ }^{2}$ Labo of Energy and Mechanical Engineering (LEMI), Faculty of Technology, UMBB, Boumerdes, Algeria
}

\begin{abstract}
Forced convection heat transfer in channels with a block has been studied numerically. The vertical walls are differentially heated. The Lattice Boltzmann Method with multiple relaxation time (MRT) has been used to solve numerically the momentum and the heat transfer governing equations. This study details the effects of variations in the Reynolds number, Rayleigh number, and behavior index of fluid, to illustrate important fundamental and practical results. The results show that the recirculation caused by porous-covering block will significantly enhance the heat transfer rate on both top and right faces of second and subsequent blocks. In order to better understand the different elements of the study, we first analyzed the flow in a channel without obstacles in order to understand the behavior of non-Newtonian fluids. in such situations, we have observed that the speed profiles at establishment are essentially dependent on the behavior index, while the heat transfers are proportional to the Reynolds and Prandtl numbers but inversely to the behavior index.
\end{abstract}

\section{Introduction}

Studies on convective heat transfer have great relevance due to the investigation of numerous applications in engineering such as heat exchangers (design, operation, and maintenance) and electronic packaging (temperature control in equipment that operates in specific ranges and/or is limited to critical values). The temperature control is often influenced by an appropriate geometric configuration of the system [1-3]. As an example, Alves and Altemani [4] investigated the factors influencing the forced convection cooling of sources on a printed circuit board, concluding that the dimensions of the sources and their arrangement on the plate exert high influence on the flow behavior and consequently the heat exchange. As a consequence of this importance, several works related to heat exchangers with fins or obstacles can be found for vertical channels [5-11] and horizontal channels [1215].

Sun et al. [16] aims at showing that to prescribe a flow rate at the inlet section of a vertical channel with heated walls leads to surprising and counter-intuitive physical solutions, especially when the problem is modelled as elliptical. Such an approach can give rise to the onset of recirculation cells in the entry region while the heat transfer is slightly increased under the influence of buoyancy force. In addition, we have shown that to prescribe w0 yields no significant difference between the wall heat fluxes calculated either for forced convection or for mixed convection When imposing an outlet pressure drop, natural convection assists effectively forced convection and the flow rate as well as the wall heat fluxes are systematically increased over those found for pure forced convection. Harnane et al. [17] Under taken a numerical study of turbulent natural convection flow and heat transfer around a square bar with constant temperature has been performed in a vertical channel, using FDS code. The results show that the FDS code can qualitatively capture the structure of the flow field and quantitatively reproduces the mean velocities. The agreement between the measured and calculated mean values of velocities establishes the applicability of the LES model. Here, the heat transfer is improved when the bar is the highest due to the competition between natural convection and mixed convection induced by the chimney effect. Numerical simulation of flow in a channel with the presence of solid block is carried out by Zaman et al. [18]. The block aspect ratio is changed while keeping the area of the block constant for all aspect ratios. The tilting angle is also incorporated analysis to examine its effect on the Nusselt number. The Nusselt number improves with reducing

\footnotetext{
* Corresponding author: lyes.nasseri@gmil.com
} 
the block aspect ratio, which is particularly true along the side faces of the block. In addition, the influence of the block tilting angle on the Nusselt number is considerable for the low block aspect ratios. Prasad et al. [19] invistigate the effect of thermal radiation and viscous dissipation on a combined free and forced convective flow in a vertical channel is investigated for a fully developed flow regime. Athors have found that the viscous dissipation enhances the flow reversal in the case of a downward flow while it counters the flow in the case of an upward flow. Natural convection heat transfer in a parallel plate channel with a heat source array has been studied experimentally and numerically by Sarper et al. [20]. The effects of the modified Grashof number and blockage ratio of the heat sources on fluid flow and cooling performance have been analyzed. Flow separation results in an increase in the average Nusselt number on the downstream surface of the last heat source compared with the first three heat sources at $\mathrm{br}=0.5$ (br : heat source blockage ratio) An increase in the blockage ratio increase fluctuation of the fluid, and it causes a transition from laminar to turbulent flow regime.

In the case of a non-Newtonian fluid in a vertical channel. Bhowmick et al. [21] have studied the problem of nonNewtonian mixed convection boundary-layer flow along an isothermal horizontal circular cylinder, solved by the modified power-law method. They found that heating the cylinder delays separation and if the cylinder is warm enough, suppress it completely. Ayoubi et al. [22] have conducted a theoretical study of free convection flow and heat transfer of a non-Newtonian fluid with pseudoplastic behavior in a cylindrical vertical cavity partially filled with a layer of a porous medium. The influence of the thickness of the porous layer, Rayleigh number and nonNewtonian index on the heat transfer behavior of a non-Newtonian pseudoplastic fluid is conducted. The increase of pseudoplastic behavior and increase of the thickness of the porous layer enhances the heat transfer. By increase of the porous layer from 0.6 to 0.8 , the average Nusselt number increased from 0.15 to 0.25 . The increase of nonNewtonian effects (decrease of the non-Newtonian power-law index) enhances the heat transfer rate.

In this investigation, the behavior of non-Newtonian fluids laminar flow on the forced convection along a differentially heated vertical plane are studied by choosing the power-law index as $n(=0.25,1.5)$ to fully demonstrate the performance of various pseudo-plastic fluids. The numerical solutions are based on the Reynolds number Re, Prandtl number Pr and power-law index n. The results refer to the Nusselt number, as well as to the velocity and temperature profiles. Results are given in the form of tables and graphs, as well. The mean objective of this study, is to compare the impact of rectangular block on fluid flow and heat transfer.

\section{Mathematical formulation}

We propose in this section the study of the flow of a non-Newtonian fluid which follows a rheological law of the power law type, between two vertical and parallel flat plates of length L, separated from each other by a distance $\mathrm{H}$. The first scenario considered is a flow in the channel without obstacles, the fluid begins to flow in the channel with a speed U0 (velocity reference) and a temperature Tc (Cold temperature). We performed a parametric study to see the influence of fluid flow parameters on heat and momentum transfers.

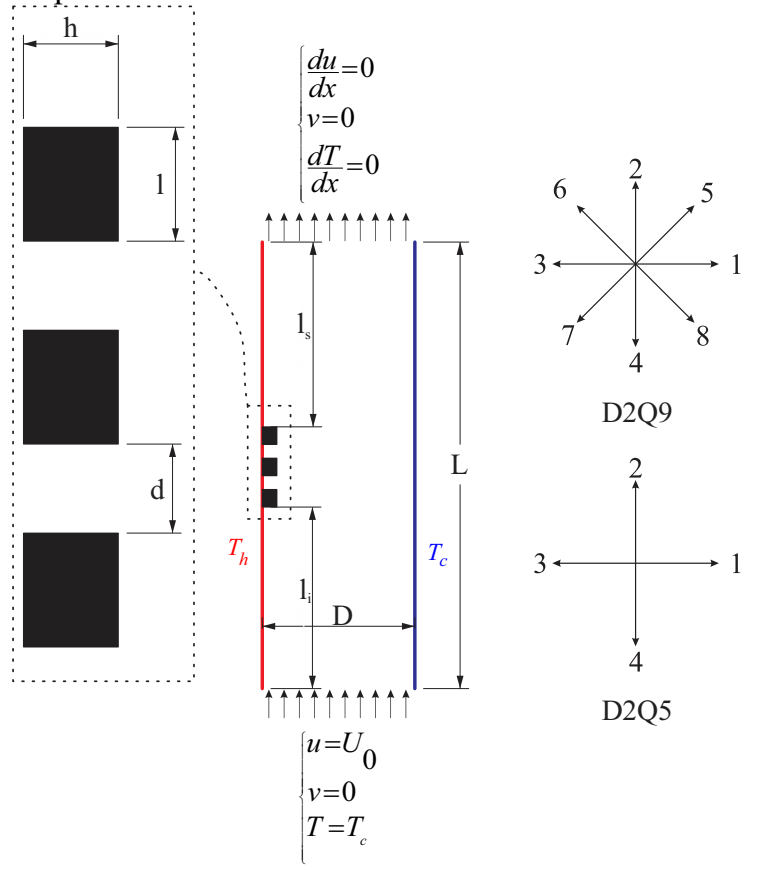

Fig. 1. Physical model 
The control parameters are: the Prandtl number (Pr), the fluid behavior index (n) and the Reynolds number (Re). In the second case, we will see the influence of the three rectangular obstacles separated by distances (d), expressed as a function of the unit width of the channel, on the heat transfers in the flow by the same parametric study already carried out. Figure .1 illustrates a physical model studied in the configuration where rectangular obstacles are placed in the channel.

The two-dimensional flow is considered laminar stationary with incompressible fluid. Under theses simplifying assumptions, the dimensionless governing equations are written as follows:

$$
\begin{gathered}
\frac{\partial \mathrm{u}^{\prime}}{\partial \mathrm{x}^{\prime}}+\frac{\partial \mathrm{v}^{\prime}}{\partial \mathrm{y}^{\prime}}=0 \\
\frac{\partial u^{\prime}}{\partial t^{\prime}}+\frac{\partial\left(u^{\prime} u^{\prime}\right)}{\partial x^{\prime}}+\frac{\partial\left(v^{\prime} u^{\prime}\right)}{\partial y^{\prime}}=-\frac{\partial P^{\prime}}{\partial x^{\prime}}+\frac{\eta^{\prime}}{\operatorname{Re}}\left(\frac{\partial^{2} u^{\prime}}{\partial x^{\prime 2}}+\frac{\partial^{2} u^{\prime}}{\partial y^{\prime 2}}\right)+\frac{2}{\operatorname{Re}}\left(\varepsilon_{x^{\prime} x^{\prime}}^{\prime} \frac{\partial \eta^{\prime}}{\partial x^{\prime}}+\varepsilon_{y^{\prime} x^{\prime}}^{\prime} \frac{\partial \eta^{\prime}}{\partial y^{\prime}}\right) \\
\frac{\partial v^{\prime}}{\partial t^{\prime}}+\frac{\partial\left(u^{\prime} v^{\prime}\right)}{\partial x^{\prime}}+\frac{\partial\left(v^{\prime} v^{\prime}\right)}{\partial y^{\prime}}=-\frac{\partial P^{\prime}}{\partial y^{\prime}}+\frac{\eta^{\prime}}{\operatorname{Re}}\left(\frac{\partial^{2} v^{\prime}}{\partial x^{\prime 2}}+\frac{\partial^{2} v^{\prime}}{\partial y^{\prime 2}}\right)+\frac{2}{\operatorname{Re}}\left(\varepsilon_{x^{\prime} y^{\prime}}^{\prime} \frac{\partial \eta^{\prime}}{\partial x^{\prime}}+\varepsilon_{y^{\prime} y^{\prime}}^{\prime} \frac{\partial \eta^{\prime}}{\partial y^{\prime}}\right) \\
\frac{\partial T^{\prime}}{\partial t^{\prime}}+\frac{\partial\left(u^{\prime} T^{\prime}\right)}{\partial x^{\prime}}+\frac{\partial\left(v^{\prime} T^{\prime}\right)}{\partial y^{\prime}}=\frac{1}{P e}\left(\frac{\partial^{2} T^{\prime}}{\partial x^{\prime 2}}+\frac{\partial^{2} T^{\prime}}{\partial y^{\prime 2}}\right) \\
\left.\left.\varepsilon_{x^{\prime} x^{\prime}}^{\prime}=\frac{\partial}{\partial u^{\prime}} \frac{\partial u_{i}^{\prime}}{\partial x_{i}^{\prime}}+\frac{\partial u_{j}^{\prime}}{\partial x_{j}^{\prime}}\right]{ }_{i}\right] \varepsilon_{y^{\prime} y^{\prime}}^{\prime}=\frac{\partial v^{\prime}}{\partial y^{\prime}} \quad \varepsilon_{x^{\prime} y^{\prime}}^{\prime}=\varepsilon_{y^{\prime} x^{\prime}}^{\prime}=\frac{1}{2}\left[\frac{\partial u^{\prime}}{\partial y^{\prime}}+\frac{\partial v^{\prime}}{\partial x^{\prime}}\right]
\end{gathered}
$$

Where $\operatorname{Re}=\frac{\rho U_{r e f}^{2-n} l_{r e f}^{n}}{m}, \operatorname{Pr}=\frac{m C_{p}}{k}\left(\frac{U_{r e f}}{l_{r e f}}\right)^{n-1}$ and $P e=\operatorname{Re} \cdot \operatorname{Pr}$ with $\alpha=\frac{k}{\rho C_{p}}$.

These parameters represent respectively the Reynolds numbers, the Prandtl number and the Peclet number, relating to a non-Newtonian fluid of the power law type.

Taking:

$$
\eta_{0}=m\left(\frac{U_{r e f}}{l_{r e f}}\right)^{n-1}
$$

We find the form of these last dimensionless numbers:

$$
\begin{gathered}
\operatorname{Re}=\frac{\rho U_{r e f} l_{r e f}}{\eta_{0}} \\
\operatorname{Pr}=\frac{\eta_{0} C_{p}}{k}
\end{gathered}
$$

The heat transfer is measured by local Nusselt number which can be written as:

$$
N u_{x}=\frac{h l}{k}
$$

The average Nusselt number can be obtained by:

$$
\overline{N u}=\int N u_{x}
$$

\subsection{Dynamic boundary conditions:}

The left and right walls are fixed and raincoat. The fluid checks the condition of adhesion to the walls, so $\mathrm{U}=\mathrm{V}=0$;

On inlet, the fluid enters the channel at a constant velocity such as $\mathrm{V}=\mathrm{U} 0$ and leaves in steady state $\partial \mathrm{v} / \partial \mathrm{y}=0$, $\mathrm{u}=1$. 


\subsection{Thermal boundary conditions}

At the inlet, the temperature of the fluid is equal to $\mathrm{Tc}=0$ (cold temperature). The temperature of the left wall is Th (hot temperature), that of the right wall is Tc;

At the outlet of the channel the thermally established regime implies: $\partial \mathrm{T} / \partial \mathrm{y}=0$;

The dimensions of the channel are taken so as to check the thermal and dynamic conditions of the flow (taking into account a significant length, sufficient to have the establishment).

In the MRT-LBM model boundary conditions are needed for both velocity and temperature. In the MRT-LBM model, boundary conditions are needed for both velocity and temperature. The boundary conditions are treated as [24-26]. For the Dirichlet type case, the so-called "Bounce back" case is used to model a solid stationary or conditions at the moving and non-slip borders [27-29].

\section{Numerical method}

In this paper, the lattice Boltzmann equation using the MRT collision model with nine velocities (D2Q9 model) and D2Q5 for temperature is considered [24]. The evolution equation of the model is expressed as:

$$
f\left(\mathrm{x}+\mathrm{e}_{\mathrm{k}} \Delta \mathrm{t}, \mathrm{t}+\Delta \mathrm{t}\right)-f(\mathrm{x}, \mathrm{t})=-\mathrm{M}^{-1} \mathrm{SM}\left[f(\mathrm{x}, \mathrm{t})-f^{\mathrm{eq}}(\mathrm{x}, \mathrm{t})\right]
$$

Where $f=\left(f_{0} ; f_{1} ; f_{2} ; f_{3} ; f_{4} ; f_{5} ; f_{6} ; f_{7} ; f_{8}\right)^{\mathrm{T}}$ and $\mathrm{T}$ denotes the transpose operator. $f(\mathrm{x}, \mathrm{t})$ is 9 dimensional vectors for the distribution functions, $f^{\mathrm{eq}}(\mathrm{x}, \mathrm{t})$ is the equilibrium distribution function of $f(\mathrm{x}, \mathrm{t})$ , and computed as:

$$
f_{\mathrm{k}}^{\mathrm{eq}}=\omega_{\mathrm{k}} \rho\left[1+\frac{3}{\mathrm{c}^{2}} \mathrm{e}_{\mathrm{k}} \cdot \mathrm{u}+\frac{9}{2 \mathrm{c}^{4}}\left(\mathrm{e}_{\mathrm{k}} \cdot \mathrm{u}\right)^{2}-\frac{3}{2 \mathrm{c}^{2}} \mathrm{u} \cdot \mathrm{u}\right]
$$

Where $\mathrm{c}=\Delta \mathrm{x} / \Delta \mathrm{t}$ is the lattice speed, $\Delta \mathrm{x}$ and $\Delta \mathrm{t}$ are the lattice cell width and time step size, respectively. Here, $\Delta \mathrm{t}$ is chosen to be equal to $\Delta \mathrm{x}$, thus $\mathrm{c}=1$.

The macroscopic fluid variables, density, velocity, and pressure are calculated, respectively, as follows:

$$
\begin{gathered}
\rho(\mathrm{x}, \mathrm{t})=\sum_{\mathrm{k}=0}^{8} f_{\mathrm{k}} \\
\mathrm{u}=\frac{1}{\rho} \sum_{\mathrm{k}=0}^{8} \mathrm{e}_{\mathrm{k}} f_{\mathrm{k}} \\
\mathrm{p}=\rho \mathrm{C}_{\mathrm{s}}{ }^{2}
\end{gathered}
$$

Where $\mathrm{C}_{\mathrm{s}}=\mathrm{c} / \sqrt{3}$ is the speed of sound.

As shown in Fig. $1, \mathrm{e}_{\mathrm{k}}$ denotes the particle velocity defined as:

$$
\mathrm{e}_{\mathrm{k}}=\left\{\begin{array}{lll}
(0,0) & \mathrm{k}=0 \\
\mathrm{c}(\cos \theta, \sin \theta) & \theta=(\mathrm{k}-1) \pi / 2 & \mathrm{k}=1,2,3,4 \\
\sqrt{2} \mathrm{c}(\cos \theta, \sin \theta) & \theta=(\mathrm{k}-5) \pi / 2+\pi / 4 & \mathrm{k}=5,6,7,8
\end{array}\right.
$$

Also, $\omega_{\mathrm{k}}$ is a weighting factor in the $\mathrm{k}$ direction in the discrete velocity expressed as follows:

$$
\omega_{\mathrm{k}}= \begin{cases}4 / 9 & \mathrm{k}=0 \\ 1 / 9 & \mathrm{k}=1,2,3,4 \\ 1 / 36 & \mathrm{k}=5,6,7,8\end{cases}
$$

The evolution process of the MRT model also consists of two parts, (i.e. collision and streaming). Collision and streaming steps are written as follows, respectively:

$$
\begin{gathered}
\tilde{f}_{\mathrm{k}}(\mathrm{x}, \mathrm{t})=f_{\mathrm{k}}(\mathrm{x}, \mathrm{t})+\mathrm{M}^{-1} \mathrm{~S}\left[\mathrm{R}(\mathrm{x}, \mathrm{t})-\mathrm{R}^{\mathrm{eq}}(\mathrm{x}, \mathrm{t})\right] \\
f_{\mathrm{k}}\left(\mathrm{x}+\mathrm{e}_{\mathrm{k}} \delta \mathrm{t}, \mathrm{t}+\delta \mathrm{t}\right)=\tilde{f}_{\mathrm{k}}(\mathrm{x}, \mathrm{t})
\end{gathered}
$$


where $\tilde{f}_{\mathrm{k}}(\mathrm{x}, \mathrm{t})$ denotes the density distribution function after collision.

$\mathrm{M}$ is a $9 \times 9$ matrix which transforms $f_{\mathrm{k}}$ and $f_{\mathrm{k}}^{\mathrm{eq}}$ into the moment space with $\mathrm{R}=\mathrm{M} f$ and $\mathrm{R}^{\mathrm{eq}}=\mathrm{M} f^{\mathrm{eq}}$ where $\mathrm{R}$ and $\mathrm{R}^{\mathrm{eq}}$ are the macroscopic variables vectors. The distribution functions in the moment space are given by [24]:

The equilibrium distribution functions in moment space are defined as:

$$
\mathrm{R}_{\mathrm{eq}}=\left(\rho^{\mathrm{eq}}, \mathrm{e}^{\mathrm{eq}}, \varepsilon^{\mathrm{eq}}, \mathrm{j}_{\mathrm{x}}^{\mathrm{eq}}, \mathrm{q}_{\mathrm{x}}^{\mathrm{eq}}, \mathrm{j}_{\mathrm{y}}^{\mathrm{eq}}, \mathrm{q}_{\mathrm{y}}^{\mathrm{eq}}, \mathrm{p}_{\mathrm{xx}}^{\mathrm{eq}}, \mathrm{p}_{\mathrm{xy}}^{\mathrm{eq}}\right)^{\mathrm{T}}
$$

where the equilibrium values in the above equation can be written as:

$$
\begin{gathered}
\mathrm{e}^{\mathrm{eq}}=-2 \rho+3\left(\mathrm{j}_{\mathrm{x}}{ }^{2}+\mathrm{j}_{\mathrm{y}}{ }^{2}\right) \\
\varepsilon^{\mathrm{eq}}=\rho-3\left(\mathrm{j}_{\mathrm{x}}{ }^{2}+\mathrm{j}_{\mathrm{y}}{ }^{2}\right) / \rho_{0} \\
\mathrm{q}_{\mathrm{x}}^{\mathrm{eq}}=-\mathrm{j}_{\mathrm{x}} \\
\mathrm{p}_{\mathrm{xx}}^{\mathrm{eq}}=\left(\mathrm{j}_{\mathrm{x}}{ }^{2}-\mathrm{j}_{\mathrm{y}}{ }^{2}\right) / \rho_{0} \\
\mathrm{p}_{\mathrm{xy}}^{\mathrm{eq}}=\left(\mathrm{j}_{\mathrm{x}} \cdot \mathrm{j}_{\mathrm{y}}\right) / \rho_{0} \\
\mathrm{j}_{\mathrm{y}}^{\mathrm{eq}}=-\mathrm{j}_{\mathrm{y}}
\end{gathered}
$$

The constant $\rho_{0}$ is the mean density in the domain and is set to unity. $\mathrm{S}_{\mathrm{j}}$ are the relaxation rates; the diagonal elements of the matrix $\mathrm{S}$.

$$
\mathrm{S}=\operatorname{diag}\left(0, \mathrm{~S}_{1}, \mathrm{~S}_{2}, 0, \mathrm{~S}_{4}, 0, \mathrm{~S}_{6}, \mathrm{~S}_{7}, \mathrm{~S}_{8}\right)
$$

Due to mass and momentum conservation before and after collision, collision rates $\mathrm{S}_{0}, \mathrm{~S}_{3}$ and $\mathrm{S}_{5}$ are set zero. In the SRT collision model, the collision operator $\mathrm{S}$ is a diagonal matrix whose non-zero elements are $1 / \tau$, where $\tau$ is the dimensionless relaxation rate. But in the MRT model, the collision operator is a diagonal matrix whose elements values $S_{1}, S_{2}, S_{4}$ and $S_{6}$ can be chosen more flexibly in the range $0<S_{j}<2$. Lallemand and Lou [24] recommended that for stability reasons the values should be chosen somewhat more than unity. In this study the relaxation rates $\mathrm{S}_{1}=\mathrm{S}_{2}=\mathrm{S}_{4}=\mathrm{S}_{6}=1.1$ are used. For giving a consistent dynamics viscosity, relaxation rates $\mathrm{S}_{7}$ and $\mathrm{S}_{8}$ have to be equal. S7 and S8 are related to the dynamic viscosity $\mu$ by [24]

$$
\mu=\rho \mathrm{C}_{\mathrm{s}}^{2} \Delta \mathrm{t}\left(\frac{1}{\mathrm{~S}_{7}}-\frac{1}{2}\right)=\rho \mathrm{C}_{\mathrm{s}}^{2} \Delta \mathrm{t}\left(\frac{1}{\mathrm{~S}_{8}}-\frac{1}{2}\right)
$$

Since strain rate tensor and viscosity for non-Newtonian fluids vary with position in a flow domain, it is needed to determine the shear rate at each point in the simulation. This can be determined by the strain rate tensor:

$$
\varepsilon_{\alpha \beta}=\frac{1}{2}\left(\nabla_{\beta} \mathrm{u}_{\alpha}+\nabla_{\alpha} \mathrm{u}_{\beta}\right)
$$

One of the advantages of the LBE is that the viscous stresses can be calculated locally. The strain rate tensor e in MRT model can be derived with the following equation [30]:

$$
\varepsilon_{\alpha \beta}=\frac{1}{2 \rho C_{s}^{2} \Delta \mathrm{t}} \sum_{\mathrm{i}=0}^{8} \mathrm{e}_{\mathrm{i} \alpha} \mathrm{e}_{\mathrm{i} \beta} \sum_{\mathrm{j}=0}^{8}\left(\mathrm{M}^{-1} \mathrm{SM}\right)_{\mathrm{ij}}\left[f_{\mathrm{j}}(\mathrm{x}, \mathrm{t})-f_{\mathrm{j}}^{\mathrm{eq}}(\mathrm{x}, \mathrm{t})\right]
$$

Apparent viscosity of a power-law fluid, $\mu$, is determined as:

$$
\mu=\mu_{0}|\dot{\gamma}|^{\mathrm{n}-1}
$$

where $\mu_{0}$ is the zero-shear viscosity and $n$ is the power-law exponent. The case $n<1$ correspond to shearthinning (pseudoplastic) fluids, whereas $n>1$ correspond to shear-thickening (dilatant) fluids and $n=1$ recovers the Newtonian behavior. Strain rate is related to the symmetric strain rate tensor:

by the expression:

$$
\mathrm{D}_{\mathrm{II}}=\sum_{\alpha, \beta=1}^{\mathrm{L}} \varepsilon_{\alpha \beta} \varepsilon_{\alpha \beta}
$$

$$
\dot{\gamma}=\sqrt{\mathrm{D}_{\mathrm{II}}}
$$

where here $\mathrm{L}=2$ for a two-dimensional simulation 


\section{Results and discussion}

Figures 2, 3 and 4 illustrate the streamline evolution, of a pseudoplastic, Newtonian and dilatant fluids respectively for a Reynolds number increasing from 50 to 600 . The effect of the obstacles is very significant depending to the type of non-Newtonian fluid and the value of the Reynolds number. In general, the flow is disturbed in the region where the obstacles are placed, the streamlines are deviated towards the spaces between obstacles and fluid recirculation zones appear when the value of Reynolds number increasing. Three recirculation zones can be identified in the space between the first and second, between the second and third and just downstream of the third obstacle. The intensity of these recirculation's is greater when using a pseudoplastic fluid.

In Figure 12 we observe that from a low value of Reynolds $(\mathrm{Re}=50)$ these recirculation's take shape and expand in volume as the flow rate of the fluid increases, for $\mathrm{Re}=400$ we observe that in the spaces between obstacles, two recirculation cells of different volumes are formed, the increase in Reynolds number makes these cells to group together to form a very large cell that takes a large space. For shear thickening fluids, it is noted that the development of the three recirculation zones is slower, because it only occurs for $\operatorname{Re} \geq 300$, and only occupies small spaces compared to fluids with a behavior index less than or equal to unity $(\leq 1)$. For $\mathrm{Re}=100$, we observe a recirculation zone between the first and second obstacles while between the second and third obstacles the recirculation zone it is very small.

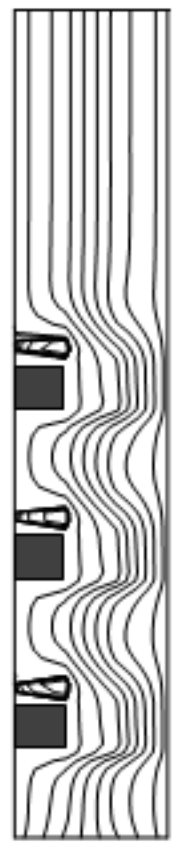

$\mathrm{Re}=100$

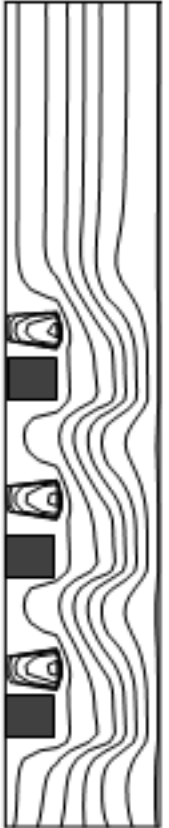

$\mathrm{Re}=300$

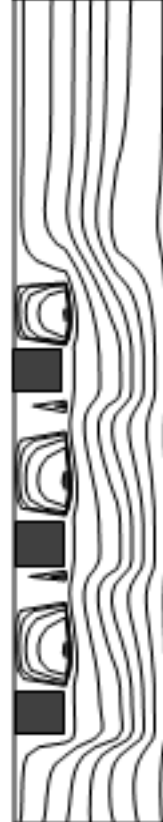

$\mathrm{Re}=400$

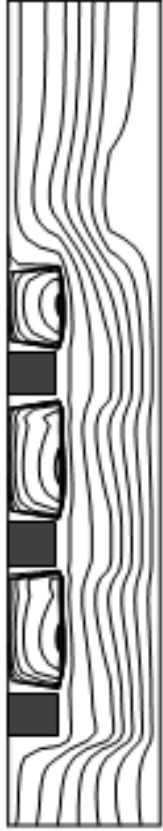

$\mathrm{Re}=600$

Fig. 2. Evolution of streamlines as a function of Reynolds number in the pseudoplastic fluid case $n=0.75$ 


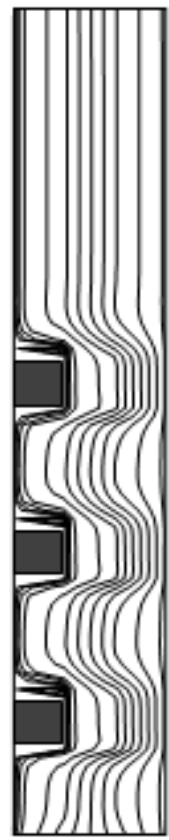

$\mathrm{Re}=100$

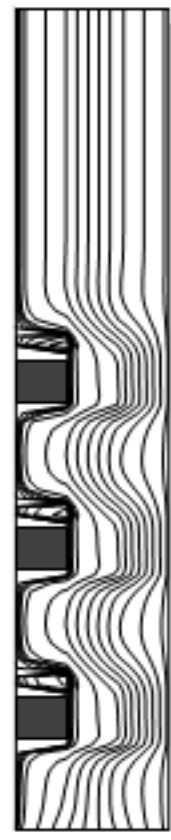

$\mathrm{Re}=300$

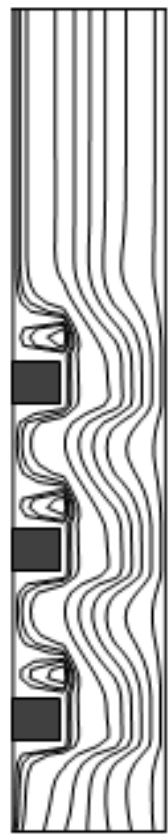

$\mathrm{Re}=400$

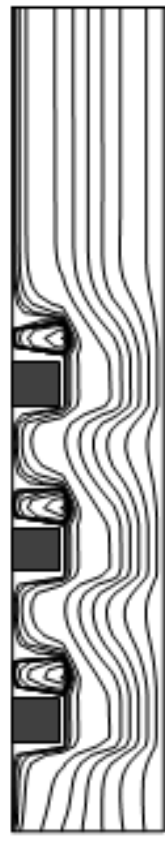

$\mathrm{Re}=600$

Fig.3. Evolutions of the streamlines versus Reynolds number for the case of Newtonian fluid $(n=1)$.

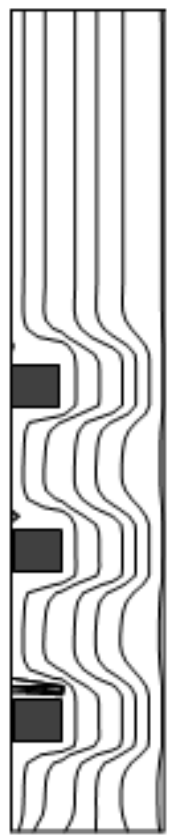

$\mathrm{Re}=100$

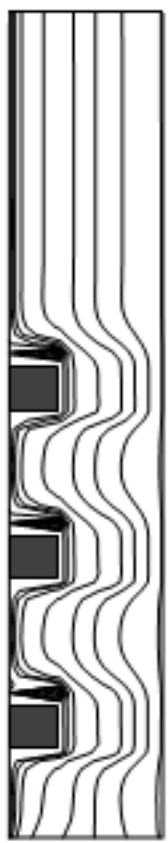

$\mathrm{Re}=300$

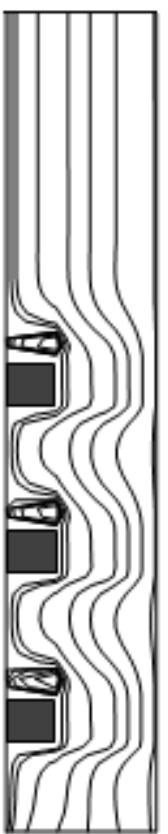

$\mathrm{Re}=400$

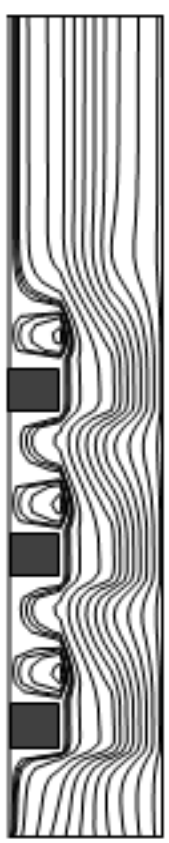

$\mathrm{Re}=600$

Fig.4. Evolutions of the streamlines versus Reynolds number for the case of dilatant fluid $(\mathrm{n}=1.5)$.

Figure 5 groups graphs representing the evolution of the average heat transfers for different indices of nonNewtonian fluid behaviour, and Prandtl's number, as a function of Reynolds. These graphs confirm that the intensity of heat transfer is inversely proportional to the behaviour index, which means that pseudo-plastic fluids are more likely to transfer temperature than dilatant or Newtonian fluids. They indicate that the introduction of obstacles increases the heat transfers for all fluids that follow the power law but in different proportions. The transfer gain is estimated at $37 \%$ for $n=0.25$ ( $\mathrm{Re}=600$ and $\mathrm{Pr}=20)$ against $18 \%$ in the case of an expanding fluid $\mathrm{n}=1.5$ and for the same Reynolds and Prandtl. The heat transfer is more important when the Reynolds number is greater, this is the consequence of the increase in the flow rates that circulate in the channel and that allow to convey more energy. 


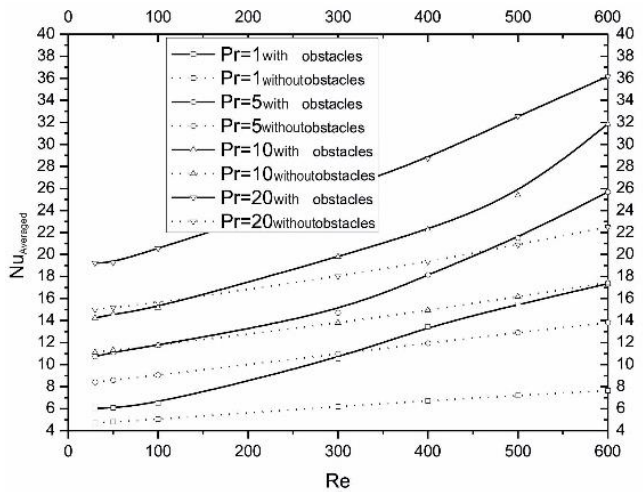

a) $n=0.25$

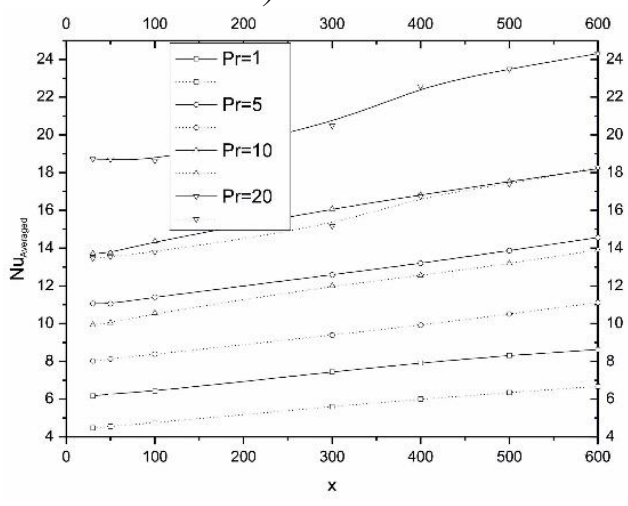

c) $n=1$

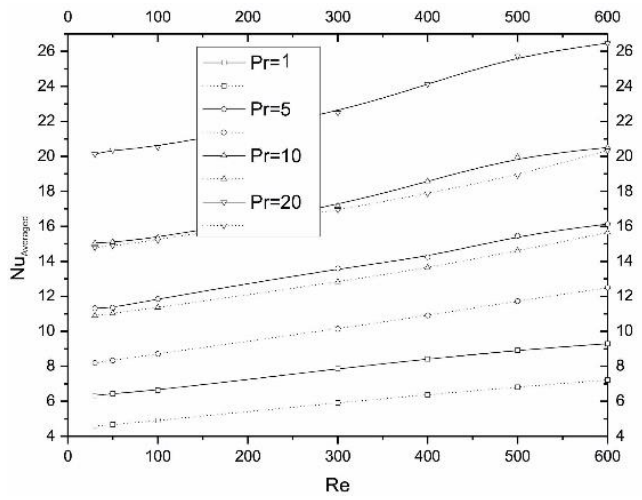

b) $n=0.75$

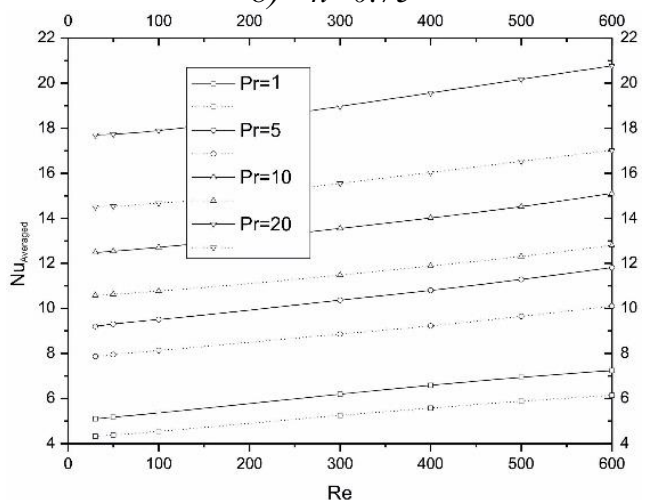

d) $n=1.5$

Fig. 5. Evolutions of the mean Nusselt number for different behavior indices and Prandtl number.

\section{Conclusions}

In this work, the problem of heat transfer of a non-Newtonian fluid has been studied numerically in a vertical channel with three obstacles mounted on the hot wall. Lattice Boltzmann Method with multiple relaxation time (LBM-MRT) has been used to resolve the conservation equations of the problem. The control parameters are Prandtl number (Pr), the fluid behavior index (n) and the Reynolds number (Re). The model was validated by the analytical solution and the results shows that principally:

- The ratio of the maximum velocities between inlet and exit is weakened when the Reynolds number increases.

- It can be observed that, for low behavior indices $\mathrm{n} \leq 0.25$, the established regime is reached from the quarter of the channel length whatever the Reynolds value. Whereas the fluid must travel more than half of its way to reach this situation for $\operatorname{Re} \geq 500$ with a higher behavior index.

- The intensity of heat transfer is inversely proportional to the behavior index. They indicate that the introduction of obstacles increases the heat transfers for all fluids that follow the power law but in different proportions. The transfer gain is estimated at $37 \%$ for $\mathrm{n}=0.25(\mathrm{Re}=600$ and $\mathrm{Pr}=20)$ against $18 \%$ in the case of a dilatant fluid $\mathrm{n}=1.5$ and for the same Reynolds and Prandtl numbers.

- Summing up the results, it can be concluded that the heat transfer is more important when the Reynolds number is greater, this is the consequence of the increase in the flow rates that circulate in the channel and that allow to convey more energy.

\section{References}

1. Himrane, N., et al., Storage Silos Self Ventilation: Interlinked Heat and Mass Transfer Phenomenon. Numerical Heat Transfer, Part A: Applications, 2014. 66(4): p. 379-401.

2. Javanmard, M., M.H. Taheri, and S.M. Ebrahimi, Heat Transfer of Third-grade Fluid Flow in a Pipe under an Externally Applied Magnetic Field with Convection on Wall \%J Applied Rheology. 2018. 28(5).

3. Rotondi, R., S. Succi, and G.J.A.R. Bella, Direct Simulation of Fluid Transport at Solid Interfaces with a Multiscale Lattice-Boltzmann Finite-Volume Method. 2004. 14(1): p. 12-21. 
4. Alves, T.A. and C.A.J.I.J.o.T.S. Altemani, An invariant descriptor for heaters temperature prediction in conjugate cooling. 2012. 58: p. 92-101.

5. Usui, T., M. Kaminaga, and Y. Sudo, Combined Forced and Free Convective Heat Transfer Characteristics in a Narrow Vertical Rectangular Channel with $2.5 \mathrm{~mm}$ in Gap Heated from Both Sides. Journal of Nuclear Science and Technology, 1989. 26(6): p. 580-590.

6. Sahoo, R.K., A. Sarkar, and V.M.K. Sastri, Effect of an Obstruction on Natural Convection Heat Transfer in Vertical Channels - a Finite Element Analysis. International Journal of Numerical Methods for Heat \& Fluid Flow, 1993. 3(3): p. 267-276.

7. Pu, W.L., P. Cheng, and T.S. Zhao, Mixed-Convection Heat Transfer in Vertical Packed Channels. Journal of Thermophysics and Heat Transfer, 1999. 13(4): p. 517-521.

8. Cruchaga, M. and D. Celentano, Modelling natural and mixed convection in obstructed channels. International Journal of Numerical Methods for Heat \& Fluid Flow, 2003. 13(1): p. 57-85.

9. Wu, H.W. and S.W. Perng, Turbulent flow and heat transfer enhancement of mixed convection over heated blocks in a channel. International Journal of Numerical Methods for Heat \& Fluid Flow, 2005. 15(2): p. 205225.

10. Oulaid, O., B. Benhamou, and N. Galanis, Flow reversal in combined laminar mixed convection heat and mass transfer with phase change in a vertical channel. International Journal of Heat and Fluid Flow, 2010. 31(4): p. 711-721.

11. Guerroudj, N. and H. Kahalerras, Mixed convection in an inclined channel with heated porous blocks. International Journal of Numerical Methods for Heat \& Fluid Flow, 2012. 22(7): p. 839-861.

12. Huang, P.C., et al., Enhancement of forced-convection cooling of multiple heated blocks in a channel using porous covers. International Journal of Heat and Mass Transfer, 2005. 48(3-4): p. 647-664.

13. Saim, R., et al., Turbulent flow and heat transfer enhancement of forced convection over heated baffles in a channel. International Journal of Numerical Methods for Heat \& Fluid Flow, 2013. 23(4): p. 613-633.

14. Ma, Y., et al., Study of nanofluid forced convection heat transfer in a bent channel by means of lattice Boltzmann method. Physics of Fluids, 2018. 30(3).

15. Teixeira, F.B., et al., Geometrical Evaluation of a Channel with Alternated Mounted Blocks under Mixed Convection Laminar Flows Using Constructal Design. Journal of Engineering Thermophysics, 2020. 29(1): p. $92-113$.

16. Sun, H., et al., On the modeling of aiding mixed convection in vertical channels. Heat and Mass Transfer, 2012. 48(7): p. 1125-1134.

17. Harnane, Y., et al., Experimental and Numerical Investigation of Turbulent Natural Convection Flow in a Vertical Channel With a Heated Obstacle. Journal of Heat Transfer, 2014. 136(10).

18. Zaman Shuja, S. and B. Yilbas, Flow over a heated block in a vertical channel. International Journal of Numerical Methods for Heat \& Fluid Flow, 2014. 24(5): p. 1044-1056.

19. Prasad, K.V., P. Mallikarjun, and H. Vaidya, Mixed Convective Fully Developed Flow in a Vertical Channel in the Presence of Thermal Radiation and Viscous Dissipation. International Journal of Applied Mechanics and Engineering, 2017. 22(1): p. 123-144.

20. Sarper, B., M. Saglam, and O. Aydin, Experimental and numerical investigation of natural convection in a discretely heated vertical channel: Effect of the blockage ratio of the heat sources. International Journal of Heat and Mass Transfer, 2018. 126: p. 894-910.

21. Bhowmick, S., M.M. Molla, and L.-S. Yao, Non-Newtonian Mixed Convection Flow along an Isothermal Horizontal Circular Cylinder. Numerical Heat Transfer, Part A: Applications, 2014. 66(5): p. 509-529.

22. Ayoubi Ayoubloo, K., et al., Pseudoplastic natural convection flow and heat transfer in a cylindrical vertical cavity partially filled with a porous layer. International Journal of Numerical Methods for Heat \& Fluid Flow, 2019. 30(3): p. 1096-1114.

23. Ghalambaz, M., K. Ayoubi Ayoubloo, and A. Hajjar, Melting heat transfer of a non-Newtonian phase change material in a cylindrical vertical-cavity partially filled porous media. International Journal of Numerical Methods for Heat \& Fluid Flow, 2019. 30(7): p. 3765-3789.

24. Lallemand, P. and L.-S. Luo, Theory of the lattice Boltzmann method: Dispersion, dissipation, isotropy, Galilean invariance, and stability. Physical Review E, 2000. 61(6): p. 6546-6562.

25. Hireche, Z., L. Nasseri, and D.E. Ameziani, Study of Periodic Thermal Exchange in a Cavity Ventilated by Displacement. Arabian Journal for Science and Engineering, 2020. 45(7): p. 5751-5768. 
26. Hireche, Z., L. Nasseri, and D.E.J.E.P.J.A.P. Ameziani, Heat transfer analysis of a ventilated room with a porous partition: LB-MRT simulations $\star$. 2020. 91(2): p. 20904.

27. Abdelkader, B., et al., Lattice Boltzmann simulation of natural convection in cubical enclosures for Bingham plastic fluid. Heat Transfer Research, 2017. 48.

28. Nasseri, L., et al., Numerical study of mixed convection in a ventilated square enclosure with the lattice Boltzmann method. 2019. 75(10): p. 674-689.

29. Nasseri, L., et al., Study of mixed convection in closed enclosure with a ceiling fan. 2019. 86(2): p. 20902.

30. Malaspinas, O., G. Courbebaisse, and M. Deville, Simulation of Generalized Newtonian Fluids with the Lattice Boltzmann Method. 2007. 18: p. 1939. 